\title{
Research on the Role of Photocatalytic Oxidation in the Deodorization of Industrial Wastes Chengtao Chen
}

School of Environmental Science and Engineering, North China Electric Power University, Baoding 071000, China.

itsme_chen@163.com

Keywords: Photo catalytic reaction, Deodorant, Industrial wastes.

Abstract. In this article, we will study the principle of photo catalytic reaction and explore the chemical reaction occurring in the process of deodorization of industrial wasting gas with the combination of the actual situation of Chinese modern factory .We will analyze the reaction principle by using some actual gas. Then, we will analyze the data obtained from the experiments which are carried out in the factory equipped with the device and draw some relatively clear charts which are easier to understand than the rough data. Then we are going to make some statements based on the result. Finally, we will evaluate the advantages and feasibility of the technology in the practical application according to the analysis and research above.

\section{Introduction}

Photo catalytic oxidation reaction is the process of using the semiconductor material as a catalyst to oxidize the refractory organics with the synergistic effect of uv-light and ozone.

Stink gases, refers to the gases which can stimulate our olfactory organs and do damage to our living environment. The reason why people are so sensitive about it is that itself has extra electrons [1].

\section{Symbols, Terminology Definitions}

Symbols and Definitions

Table1 Parameters of the Einstein's formula

\begin{tabular}{ccc}
\hline Parameter & Meaning & Units \\
\hline$E$ & The energy to combine the Molecular & $\mathrm{KJ} \cdot \mathrm{mol}^{-1}$ \\
$N_{0}$ & Avogadro constant & Unitless \\
$h$ & Planck constant & $\mathrm{J} \cdot \mathrm{S}$ \\
$v$ & The frequency of the photon & $\mathrm{HZ}$ \\
$c$ & The speed of the photon & $\mathrm{m} \bullet \mathrm{s}^{-1}$ \\
$\lambda$ & The wavelength of the photon & $\mathrm{m}$ \\
\hline
\end{tabular}

\section{The photo catalytic reaction}

We consider the titanium dioxide as the example of all photocatalyts. Under the stimulation of uv-light, the electron in the valence band will be emitted to the conduction band after absorbing some photons whose wavelength is less than a certain value. Then it becomes an active and isolated one, at the same time, some holes will be produced in the valence band correspondingly and the hole-electron pairs will generate. 


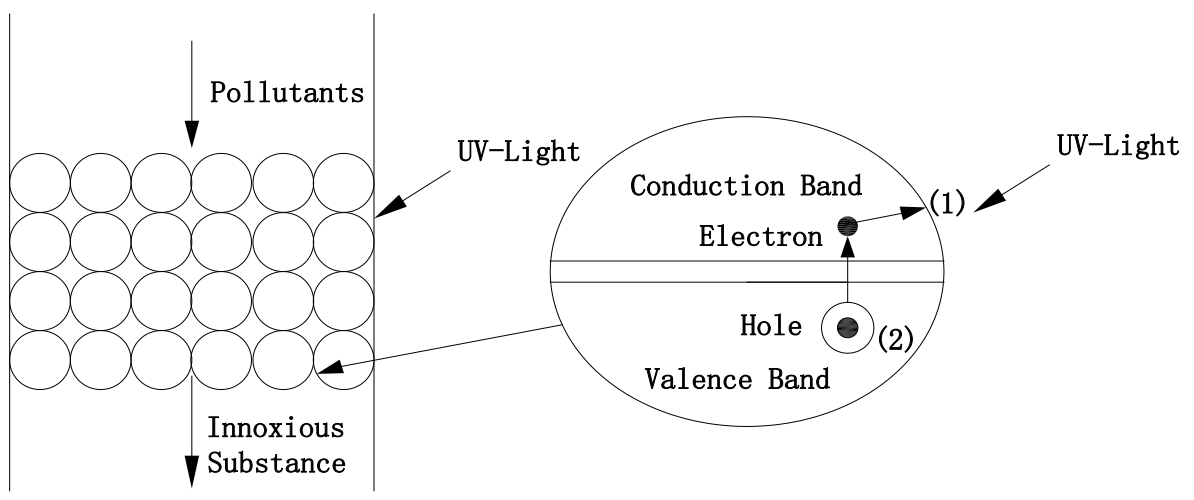

Figure 1 Photochemical reaction of titanium dioxide

The light produced electrons marked (1) have very strong reduction, so $\mathrm{O}_{2}$ can capture them to change to $\mathrm{O}_{2}^{-}$.

$$
e^{-}+\mathrm{O}_{2} \rightarrow \mathrm{O}_{2}^{-}
$$

The light-generated holes marked (2) have very strong oxidation, and they can oxidize $\mathrm{OH}^{-}$ and $\mathrm{H}_{2} \mathrm{O}$ that attached to the surface of $\mathrm{TiO}_{2}$ to $\bullet \mathrm{OH}$ [2].

$$
\begin{gathered}
b^{+}+\mathrm{H}_{2} \mathrm{O} \rightarrow \mathrm{HO} \bullet+H^{+} \\
b^{+}+\mathrm{H}_{2} \mathrm{O} \rightarrow \mathrm{HO} \cdot
\end{gathered}
$$

In the meantime, $\mathrm{O}_{2}^{-}$and $\mathrm{HO} \cdot$ have very strong oxidizability, as a result, the organics can be oxidized into $\mathrm{CO}_{2}$ and $\mathrm{H}_{2} \mathrm{O}$.

\section{The Photocatalytic reaction in deodorization}

The odor substances in industrial emissions consist of ammonia, trimethylamine, hydrogen sulfide, methyl mercaptan, methyl sulfide, dimethyl disulfide, carbon disulfide, styrene and so on.

According to the Einstein formula

$$
E=N_{0} h v=N_{0} h c / \lambda
$$

as well as the binding energy of certain chemical bond (table 2), we can calculate the wavelength of a majority of the odor gases that are split into free ions and react with ozone to generate carbon

\begin{tabular}{|c|c|c|c|}
\hline Chemical bond & $\begin{array}{c}\text { Binding energy } \\
\left(\mathrm{KJ} \cdot \mathrm{mol}^{-1}\right)\end{array}$ & Chemical bond & $\begin{array}{c}\text { Binding energy } \\
\left(\mathrm{KJ} \cdot \mathrm{mol}^{-1}\right)\end{array}$ \\
\hline $\mathrm{H}-\mathrm{H}$ & 436 & $\mathrm{C}-\mathrm{H}$ & 414 \\
\hline $\mathrm{N}-\mathrm{H}$ & 391 & $\mathrm{~S}-\mathrm{H}$ & 339 \\
\hline $\mathrm{C}=\mathrm{C}$ & 607 & $\mathrm{C} \equiv \mathrm{C}$ & 829 \\
\hline $\mathrm{C}-\mathrm{N}$ & 291 & $\mathrm{C} \equiv \mathrm{N}$ & 791 \\
\hline $\mathrm{N}-\mathrm{N}$ & 161 & $\mathrm{O}-\mathrm{H}$ & 463 \\
\hline $\mathrm{C}-\mathrm{O}$ & 352 & $\mathrm{C}=\mathrm{O}$ & 724 \\
\hline $\mathrm{O}-\mathrm{O}$ & 491 & $\mathrm{O}=\mathrm{O}$ & 463 \\
\hline
\end{tabular}
dioxide and water, in which the split is stimulated by the energy of the photons provided by UV irradiation

Table 2 Binding energy of some chemical molecules

Next we will take the example of photolysis of ammonia to analyze mechanism of the reaction in detail. The ultraviolet light with high energy can decompose the ammonia into separate atoms, then the separate atoms can react with the ozone generated by air, and finally they recombine into a low molecular compound. 


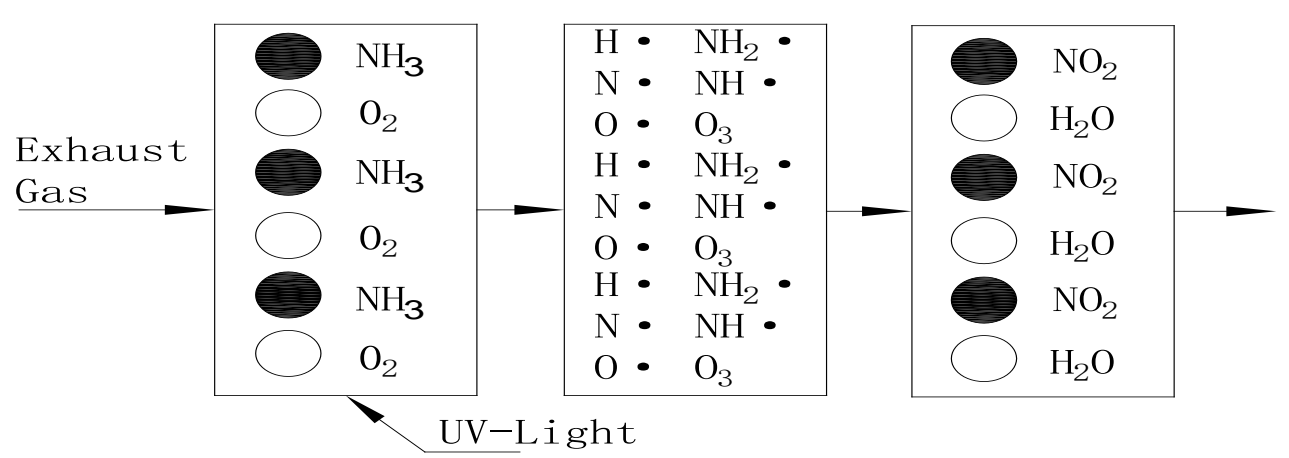

Figure 2 Diagram of photolysis of ammonia

\section{Qualitative and quantitative analysis of the experimental data}

We have done some experiments in the factory equipped with the deodorant to measure the ammonia concentration for the same time before and after the deodorization. In order to ensure the accuracy of the result, we make four measurements under the same condition.

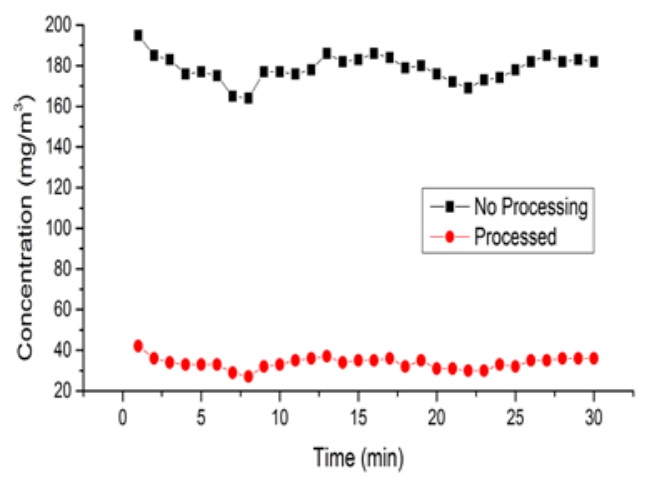

Figure 3 The first monitoring data

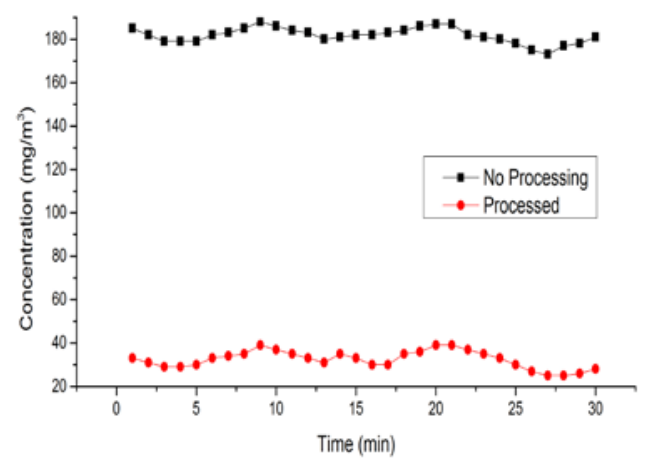

Figure 5 The third monitoring data

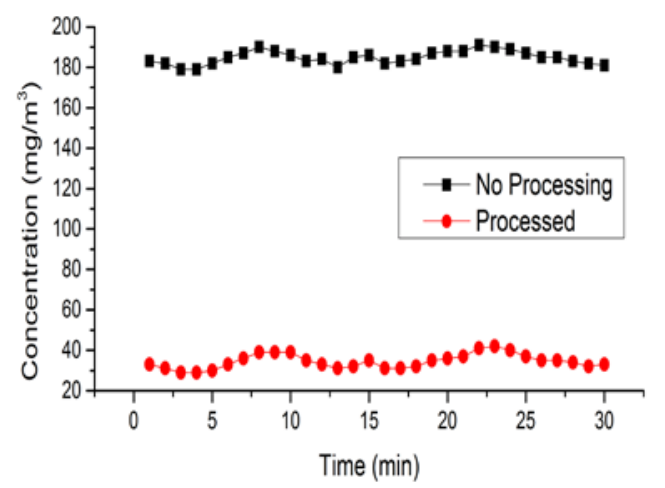

Figure 4 The second monitoring data

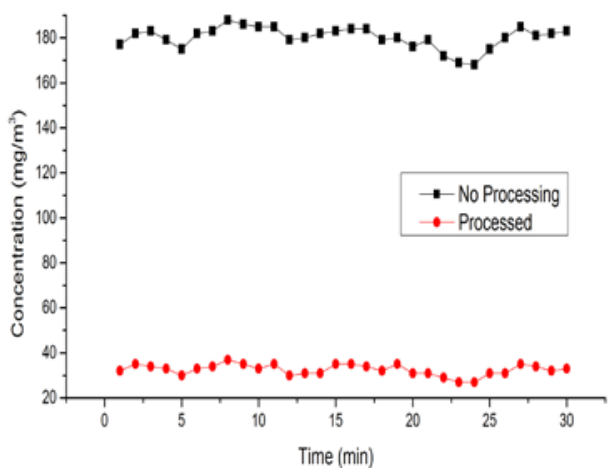

Figure 6 The fourth monitoring data

From the charts we can see the concentration of the odor gas appears a significant decline after the treatment, falling to approximate $20 \%$ of the original results.

\section{Summary}

Photocatalytic oxidation is more efficient and effective than other technologies in the treatment of industrial waste gases. What's more, the equipment is more simple and the cost is relatively low. Even there is no secondary pollution. All these reasons can explain that it is more practical and feasible than others. 


\section{Reference}

[1] Zheng Wang, Benfeng Li, Yucheng Ma, et al. Application on high energy UV photolysis technology removing odor in wastewater treatment plant[J],Petrochemical Safety and Environmental Protection Technology, 2013,29(6):61-64.

[2]Hai Qi, Jihua Wen, Yuehong Zhu, et al. Deodorization Experiment of $\mathrm{TiO}_{2}$ functional powder [J], Science Technology and Engineering, 2007,7(7):1428-1429.

[3]Changyong Wang. Odor treatment device and photoelectric ion deodorant device [J], Metallurgical Power, 2008,8:65-67.

[4] Peipei Yu, Jun Zuo. The feasibility of nano photocatalyst technology in removing odors from MSW transfer station[J], Technology Trend:41. 